\title{
Risk factors of brain metastases in completely resected pathological stage IIIA-N2 non-small cell lung cancer
}

Xiao Ding ${ }^{1}$, Honghai Dai ${ }^{1,3}$, Zhouguang Huil, Wei $\mathrm{Ji}^{1}$, Jun Liang ${ }^{1}$, Jima Lv ${ }^{1}$, Zongmei Zhou' ${ }^{1}$, Weibo Yin , Jie $\mathrm{He}^{2}$ and Luhua Wang ${ }^{1 *}$

\begin{abstract}
Background: Brain metastases (BM) is one of the most common failures of locally advanced non-small cell lung cancer (LA-NSCLC) after combined-modality therapy. The outcome of trials on prophylactic cranial irradiation (PCI) has prompted us to identify the highest-risk subset most likely to benefit from $\mathrm{PCl}$. Focusing on patients with completely resected pathological stage IIIA-N2 (pIIIA-N2) NSCLC, we aimed to assess risk factors of BM and to define the highest-risk subset.
\end{abstract}

Methods: Between 2003 and 2005, the records of 217 consecutive patients with plIIA-N2 NSCLC in our institution were reviewed. The cumulative incidence of BM was estimated using the Kaplan-Meier method, and differences between the groups were analyzed using log-rank test. Multivariate Cox regression analysis was applied to assess risk factors of BM.

Results: Fifty-three (24.4\%) patients developed BM at some point during their clinical course. On multivariate analysis, non-squamous cell cancer (relative risk [RR]: $4.13,95 \% \mathrm{Cl}: 1.86-9.19 ; \mathrm{P}=0.001$ ) and the ratio of metastatic to examined nodes or lymph node ratio (LNR) $\geq 30 \%$ (RR: 3.33 , $95 \%$ Cl: 1.79-6.18; P =0.000) were found to be associated with an increased risk of BM. In patients with non-squamous cell cancer and LNR $\geq 30 \%$, the 5 -year actuarial risk of BM was $57.3 \%$.

Conclusions: In NSCLC, patients with completely resected pIIIA-N2 non-squamous cell cancer and LNR $\geq 30 \%$ are at the highest risk for $\mathrm{BM}$, and are most likely to benefit from $\mathrm{PCl}$. Further studies are warranted to investigate the effect of $\mathrm{PCl}$ on this subset of patients.

Keywords: Non-small cell lung cancer, Brain metastases, Prophylactic cranial irradiation, Risk factors, Non-squamous cell cancer, Lymph node ratio

\section{Background}

Non-small cell lung cancer (NSCLC) comprises approximately $85 \%$ of lung cancer. Locally advanced (LA)NSCLC comprises approximately $31-44 \%$ of NSCLC. The risk of developing brain metastases (BM) in patients with early stage NSCLC is $10 \%$.[1] However, the risk of $\mathrm{BM}$ after treatment for LA-NSCLC is much higher, approximately $30-50 \%$.[1-6] BM is a devastating issue with a striking impact on survival and quality of life.

\footnotetext{
* Correspondence: wlhwq@yahoo.com

'Department of Radiation Oncology, Cancer Hospital \& Institute, Chinese Academy of Medical Sciences and Peking Union Medical College, Pan jia yuan nan li 17\#, Chao yang District, Beijing 10021, China

Full list of author information is available at the end of the article
}

Advances in surgical and radiation techniques have diminished locoregional relapse of LA-NSCLC. Systemic chemotherapy has reduced the risk of extracranial metastases. Combined-modality therapy significantly increases survival. Recent studies employing multimodality therapy have reported median survival ranging from 20 to 43 months and 3-year survival rates of $34-63 \%$ for LA-NSCLC.[7-13] However, chemotherapy has limited impact on $\mathrm{BM}$ because drugs do not easily penetrate the blood-brain barrier $(\mathrm{BBB})$, which leaves the brain relatively undertreated. $[5,14,15]$ The risk of $\mathrm{BM}$ increases as survival improves. Several studies have demonstrated that longer survival for patients with LA-NSCLC is

\section{Biomed Central}

(c) 2012 Ding et al.; licensee BioMed Central Ltd. This is an Open Access article distributed under the terms of the Creative Commons Attribution License (http://creativecommons.org/licenses/by/2.0), which permits unrestricted use, distribution, and reproduction in any medium, provided the original work is properly cited. 
associated with an increased incidence of $\mathrm{BM}$, and that $\mathrm{BM}$ becomes a rising concern, detrimental to survival. $[15,16]$ Therefore, decreasing the risk of BM becomes increasingly significant for achieving prolonged survival.

Prophylactic cranial irradiation (PCI) has shown effectiveness in small-cell lung cancer (SCLC). Notwithstanding a decrease in the incidence of $\mathrm{BM}$, randomized trials have failed to prove the survival benefit from PCI in NSCLC. [17-20] Death from local and extracranial progression may have overwhelmed any apparent benefit from PCI. The outcome of RTOG 0214 in the modern era of combinedmodality therapy, which implies that not all patients with LA-NSCLC should receive PCI, has prompted us to identify the subset, at the highest risk of BM, and most likely to benefit from PCI. Such candidates are most likely to be found in stage IIIA (N2), in that early stage has a relatively low BM risk, while stage IIIB has a relatively poor locoregional and extracranial control to obscure any potential survival benefits that PCI may have conferred.

Previous studies on risk factors of BM in NSCLC often have conflicting results and heterogeneous populations. We focused on patients with completely resected pathological stage IIIA-N2 (pIIIA-N2) NSCLC, and assessed risk factors for developing BM. Finally, we defined the highest-risk subset most likely to benefit from PCI.

\section{Methods \\ Patients}

We reviewed the records of 221 consecutive patients with completely resected pIIIA-N2 NSCLC who had survived no less than 4 months after surgery between January 2003 and December 2005 in our institution. Stage was recorded based on the American Joint Committee on Cancer staging system $\left(6^{\text {th }}\right)$.[21] Patients who presented with synchronous primary tumors, or had a prior history of lung cancer were excluded from this study. Medical records and follow-up data were reviewed to obtain patient and treatment characteristics, and to score recurrence pattern after surgery. All patients had negative brain computed tomography $(\mathrm{CT})$ scan or magnetic resonance imaging (MRI) as part of their initial staging preoperatively. Informed consent was obtained from every subject.

\section{Surgery}

The patients had lobectomy or ipsilateral pneumonectomy. Complete mediastinal lymph node dissection or systematic mediastinal lymph node sampling was performed during surgery. Complete resection was defined as resection of all macroscopic tumor and margins free of tumor at microscopic analysis.

\section{Chemotherapy}

Adjuvant chemotherapy was routinely administered except for patients with asthenia or refusal to chemotherapy and given at the discretion of the treating physicians, with a cisplatin or paclitaxel-based regimen and a median of 4 cycles.

\section{Radiotherapy}

Postoperative radiotherapy (PORT) was administered at the discretion of the attending radiation oncologist and the suggestion of the referring surgeon. Threedimensional conformal radiotherapy (3DCRT) and conventional 2-dimensional radiotherapy (2DRT) were administered with a linear accelerator using 6-8 MV xray at 2 Gy per fraction, 5 days per week, to a total dose of $60 \mathrm{~Gy}$.

\section{Follow-Up}

Patients were followed up every 3 months for the first year, then twice a year for the following 2 years, and yearly thereafter. All patients were evaluated with a physical examination, complete blood count, serum biochemistry, thoracic CT scans, abdomen B-ultrasound examination, and other necessary examinations based on the patient's symptoms. Follow-up brain MRI was performed upon development of suspicious symptoms or as part of restaging at the time of disease recurrence or yearly. Sites of disease progression or relapse were determined either radiologically or histologically. Both the initial and the subsequent sites of recurrence were documented.

\section{Data analysis}

A failure event for overall survival (OS) was defined as death of any cause. A failure event for disease-free survival (DFS) was defined as the earliest event of death of any cause, locoregional recurrence, distant recurrence, or second primary tumor. Locoregional relapse was defined as progression or recurrence at primary lung sites, or within the hilar, mediastinal, or supraclavicular lymph node regions. A distant relapse was defined as a recurrence in the other regions outside the local area such as bone, liver, adrenal glands, contralateral lung, and brain. Time to event was measured from the date of surgery to the date of failure or to the date of last follow-up if no failure occurred. The cumulative incidence of $\mathrm{BM}$ and survival were estimated by Kaplan-Meier method. Log-rank test was used to compare the difference between groups. The Cox regression was used to assess the strength of association between time to development of BM and clinical and pathological risk factors. Variables included gender, age, smoking history, site of primary tumor, histology, tumor size, tumor stage, histologic grade, adjuvant chemotherapy, PORT, number of metastatic lymph nodes, ratio of metastatic to examined nodes or lymph node ratio (LNR), number of metastatic mediastinal lymph nodes, number of 
metastatic mediastinal lymph nodes station, and ratio of metastatic mediastinal lymph nodes station. The correlation between each of the variables was determined by the chi-square test. When two variables were significantly correlated, the variable more significantly linked to the risk of $\mathrm{BM}$ was included in the multivariate analysis. Multivariate Cox regression analysis assessed risk factors for development of BM. In the multivariate Cox regression model, all variables with $\mathrm{P}$ values $<.10$ in the univariate analysis were included. All statistical tests were two-tailed, and P $<.05$ was considered significant. SPSS 18.0 was used for all statistical analyses.

\section{Results}

\section{Patient characteristics}

Among the 221 patients included in the study, 4 were excluded due to incomplete data of relapse pattern. Therefore, 217 patients were analyzed. Median followup time for the 55 surviving patients was 71.3 months (range, 58.7-103.5 months). The patient and treatment characteristics are shown in Table 1. The median age was 60 years (range, 27-79 years). Adenocarcinoma (51.6\%) was the predominant pathological type, followed by squamous cell carcinoma (40.1\%). Of all patients, 159 (73.3\%) received adjuvant chemotherapy, and 93 (42.9\%) received PORT.

\section{Survival and recurrence pattern}

Median OS for this patient population was 38.3 months. The 1-, 2-, 3-, and 5-year OS was $84.8 \%, 65.4 \%, 51.6 \%$, and $32.7 \%$, respectively (Figure 1), and the corresponding DFS was $61.8 \%, 37.3 \%, 28.6 \%$, and $19.8 \%$, respectively (Figure 2). The 5-year OS for patients developing and not developing BM was $15.1 \%$ and $38.4 \%$, respectively $(\mathrm{P}=0.002)$.

Up to the last follow-up, of all the 217 patients, local and/or distant recurrence was identified in 168 (77.4\%); first recurrence was local only (19.4\%), local and distant (12.4\%), and distant only (45.6\%); overall recurrence was local only (12.0\%), local and distant (26.7\%), and distant only (38.7\%). Of the 142 patients who had distant recurrences, 53 (37.3\%) developed $\mathrm{BM}$. Figure 3 shows time to locoregional recurrence, and Figure 4 time to distant metastasis.

Of the 217 patients, $53(24.4 \%)$ developed BM at some point during their clinical course, $32(14.7 \%)$ recurred in the brain as their first site of failure, and 15 $(6.9 \%)$ recurred in the brain as their exclusive site of failure. The 1-, 3-, and 5-year actuarial risk of developing $\mathrm{BM}$ was $9.2 \%, 24.2 \%$, and $31.5 \%$, respectively (Figure 5). Median time from surgery to onset of BM was 16 months (range, 2.5-68.5 months).
Table 1 Patient and treatment characteristics

\begin{tabular}{lll}
\hline Characteristic & No. & $\%$ \\
\hline Gender & & \\
Male & 156 & 71.9 \\
Female & 61 & 28.1 \\
Age & & \\
$\leq 60$ & 114 & 52.5 \\
$>60$ & 103 & 47.5 \\
Weight loss & & \\
$\leq 5 \%$ & 208 & 95.9 \\
$>5 \%$ & 9 & 4.1 \\
Smoking History & & \\
Negative & 98 & 45.2 \\
Positive & 119 & 54.8 \\
Preoperative KPS score & & \\
70 & 8 & 3.7 \\
$\geq 80$ & 209 & 96.3
\end{tabular}

Preoperative hemoglobin

$<120 \mathrm{~g} / \mathrm{l} \quad 18 \quad 8.3$

$\begin{array}{lll}\geq 120 \mathrm{~g} / \mathrm{l} & 199 & 91.7\end{array}$

Preoperative clinical stage N2

No

Yes

$88 \quad 40.6$

$129 \quad 59.4$

Histology

Squamous

$87 \quad 40.1$

Adenocarcinoma $\quad 112 \quad 51.6$

Adenosquamous $\quad 12 \quad 5.5$

Large cell

$6 \quad 2.8$

Tumor stage

$\mathrm{T} 1$

$\mathrm{T} 2$

T3

$17 \quad 7.8$

$163 \quad 75.1$

$37 \quad 17.1$

Laterality

Left

$96 \quad 44.2$

Right

$121 \quad 55.8$

Location

Upper/middle lobe $\quad 135 \quad 62.2$

Lower lobe $\quad 82 \quad 37.8$

Type of surgery

Lobectomy $\quad 196 \quad 90.3$

$\begin{array}{lll}\text { Pneumonectomy } & 21 & 9.7\end{array}$

Histologic grade

Well/moderate $\quad 144 \quad 66.4$

\begin{tabular}{lll} 
Poor & 64 & 29.5 \\
\hline
\end{tabular} 
Table 1 Patient and treatment characteristics (Continued)

\begin{tabular}{|c|c|c|}
\hline NS & 9 & 4.1 \\
\hline \multicolumn{3}{|c|}{ Adjuvant chemotherapy } \\
\hline No & 58 & 26.7 \\
\hline Yes & 159 & 73.3 \\
\hline \multicolumn{3}{|c|}{ Postoperative radiotherapy } \\
\hline No & 124 & 57.1 \\
\hline Yes & 93 & 42.9 \\
\hline \multicolumn{3}{|c|}{ No. of dissected lymphonodes } \\
\hline $1-20$ & 103 & 47.5 \\
\hline $20-60$ & 114 & 52.5 \\
\hline \multicolumn{3}{|c|}{ No. of metastatic lymphonodes } \\
\hline$\leq 5$ & 112 & 51.6 \\
\hline$>5$ & 105 & 48.4 \\
\hline \multicolumn{3}{|l|}{ LNR } \\
\hline$\geq 30 \%$ & 110 & 50.7 \\
\hline$<30 \%$ & 107 & 49.3 \\
\hline \multicolumn{3}{|c|}{ No. of metastatic mediastinal lymphonodes } \\
\hline$<3$ & 107 & 49.3 \\
\hline$\geq 3$ & 110 & 50.7 \\
\hline \multicolumn{3}{|c|}{ No. of metastatic mediastinal lymphonodes station } \\
\hline 1 & 136 & 62.7 \\
\hline $2-4$ & 81 & 37.3 \\
\hline \multicolumn{3}{|c|}{ Ratio of metastatic mediastinal lymphonodes station } \\
\hline$\leq 50 \%$ & 108 & 49.8 \\
\hline$>50 \%$ & 108 & 49.8 \\
\hline NS & 1 & 0.5 \\
\hline
\end{tabular}

KPS indicates Karnofsky performance status; LNR, lymph node ratio; NS, not stated.

\section{Risk factors}

Several clinical and pathological factors were found to be associated with the development of BM on both univariate and multivariate analyses (Table 2). On univariate analysis, female $(P=0.012)$, age $\leq 60$ years $(P=0.035)$, negative smoking history $(\mathrm{P}=0.038)$, non-squamous cell cancer histology $(\mathrm{P}=0.000)$ (Figure 6), number of metastatic lymph nodes $>5(\mathrm{P}=0.000), \mathrm{LNR} \geq 30 \%(\mathrm{P}=0.000)$ (Figure 7$)$, number of metastatic mediastinal lymph nodes $\geq 3(P=0.001)$, number of metastatic mediastinal lymph nodes station of 2-4 $(\mathrm{P}=0.000)$, and ratio of metastatic mediastinal lymph nodes station $>50 \%(P=0.000)$ were associated with an increased risk of developing BM. By chi-square test, the number of metastatic lymph nodes, number of metastatic mediastinal lymph nodes, number of metastatic mediastinal lymph nodes station, and ratio of metastatic mediastinal lymph nodes station were significantly correlated with LNR (P $<0.01$ ). Therefore, only LNR, the variable most significantly linked to the risk of $\mathrm{BM}$, was included in the multivariate analysis. On multivariate analysis, non-squamous cell cancer

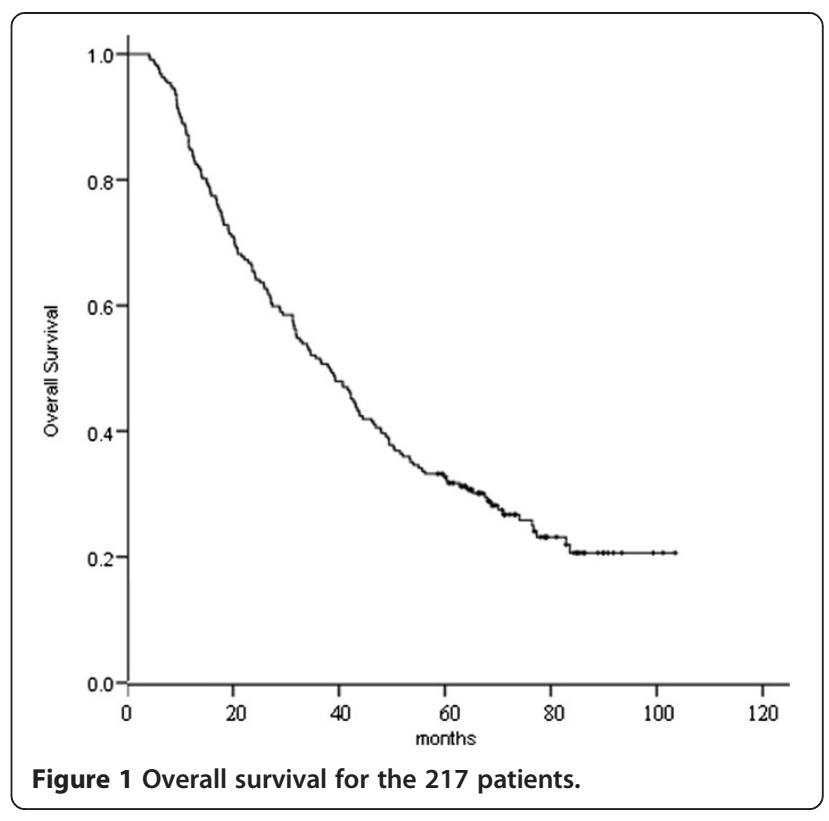

histology (RR: 4.13, $95 \%$ CI: 1.86-9.19; $\mathrm{P}=0.001$ ) and LNR $\geq 30 \%$ (RR: 3.33, $95 \%$ CI: 1.79-6.18; $\mathrm{P}=0.000$ ) were associated with an increased risk of developing BM. Identically, on multivariate analysis, non-squamous cell cancer histology (RR: 4.34, 95\% CI: 1.51-12.44; $\mathrm{P}=0.006$ ) and LNR $\geq 30 \%$ (RR: $2.35,95 \%$ CI: $1.10-5.02 ; \mathrm{P}=0.027$ ) were associated with an increased risk of $\mathrm{BM}$ as the first relapse.

In patients with non-squamous cell cancer and LNR $\geq$ $30 \%(\mathrm{n}=75)$, the 1-, 3-, and 5-year actuarial risk of developing BM was $18.1 \%, 48.6 \%$, and $57.3 \%$, respectively. In patients with non-squamous cell cancer and LNR $<30 \%(\mathrm{n}=55)$, the 1-, 3-, and 5-year actuarial risk

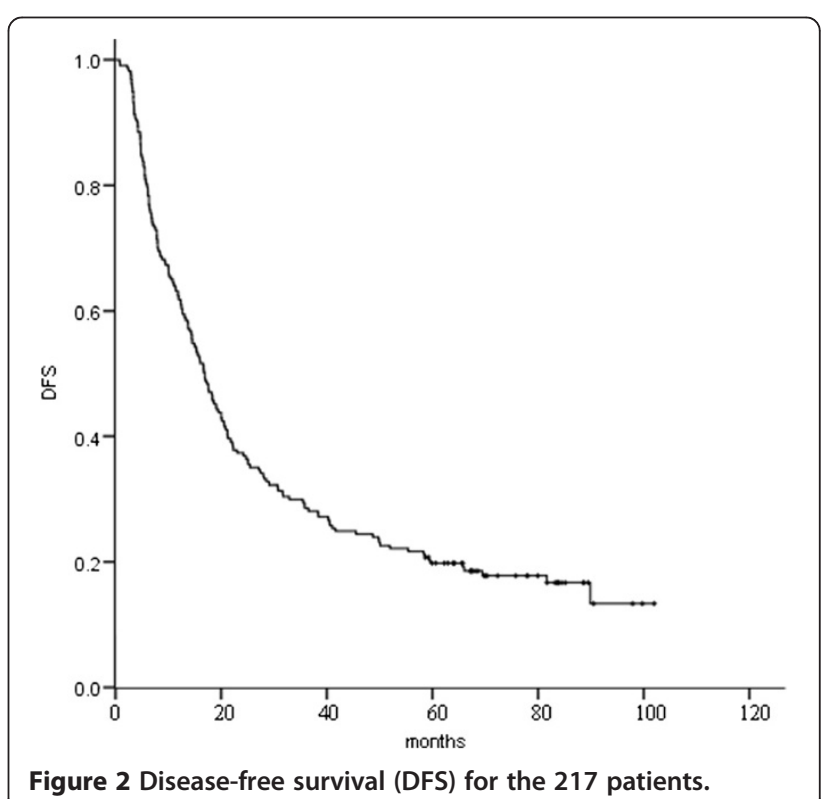




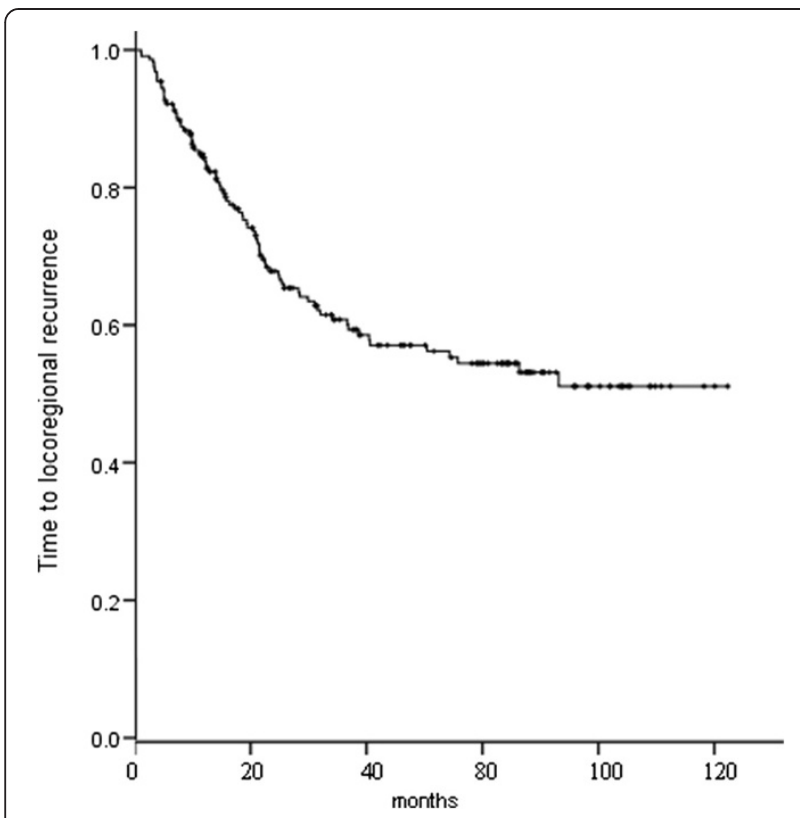

Figure 3 Time to locoregional recurrence for the 217 patients.

of developing BM was $3.8 \%, 17.5 \%$, and $28.7 \%$, respectively. In patients with squamous cell cancer and LNR $\geq$ $30 \%(\mathrm{n}=35)$, the 1-, 3-, and 5-year actuarial risk of developing BM was $9.2 \%, 18.5 \%$, and $18.5 \%$, respectively. In patients with squamous cell cancer and LNR $<30 \%(\mathrm{n}=52)$, the 1 -, 3-, and 5-year actuarial risk of developing BM was considerably lower $(2.2 \%, 2.2 \%$, and $5.3 \%$, respectively). The differences among the groups with both, one and none of the two risk factors were statistically significant $(\mathrm{P}=0.000)$ (Figure 8).

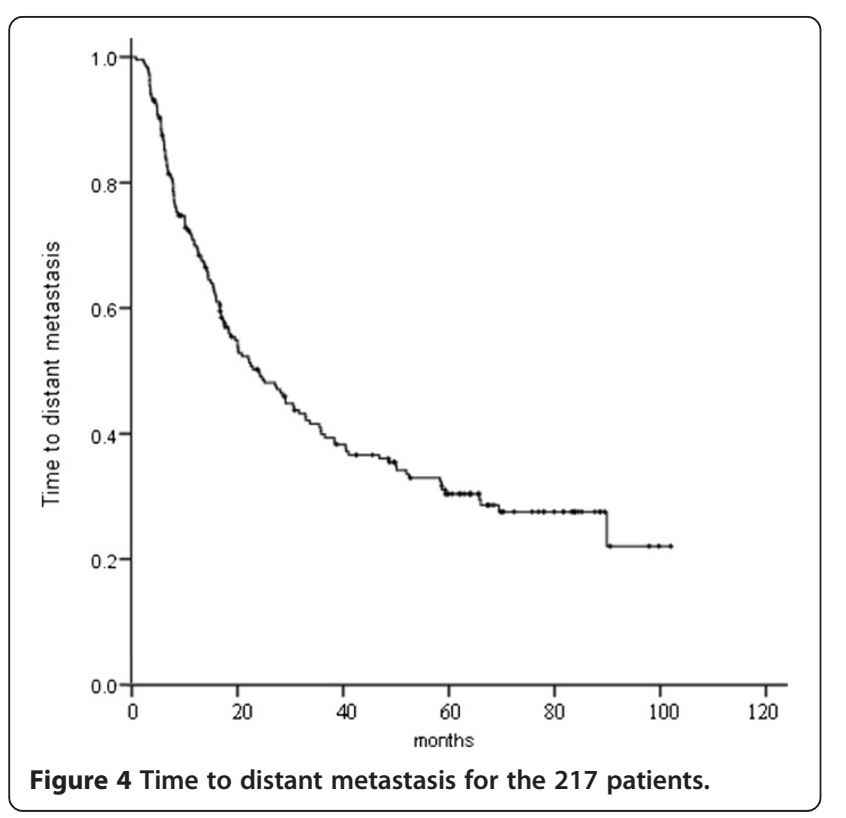

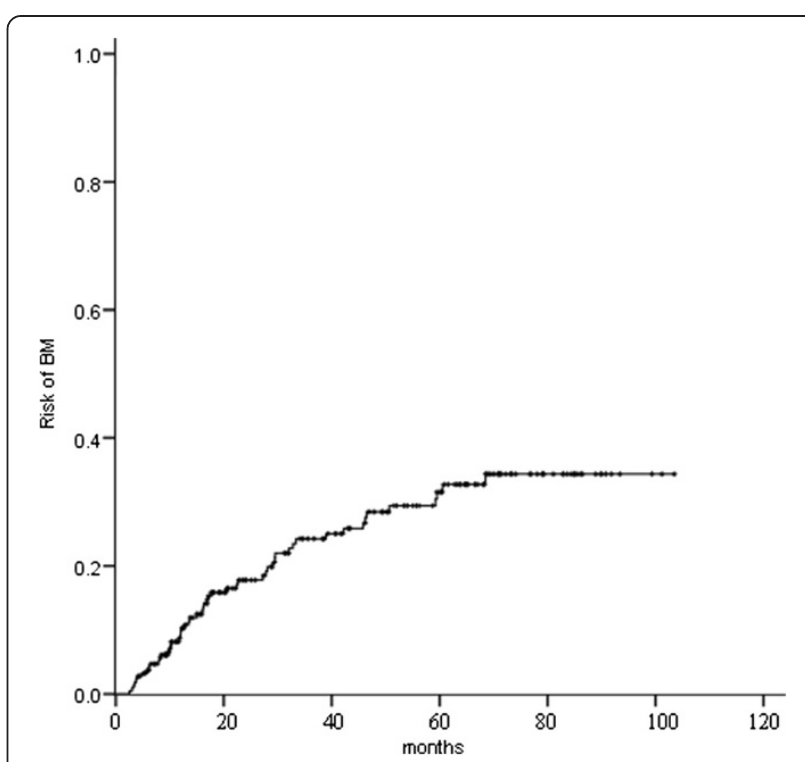

Figure 5 The actuarial risk of developing brain metastases (BM) for the 217 patients.

\section{Discussion}

With advances in surgical and radiation techniques and chemotherapy, combined-modality therapy for LANSCLC has led to improvements in locoregional and extracranial distant control, therefore in OS. Nevertheless, the risk of $\mathrm{BM}$ remains. In our study, of the 217 patients, $53(24.4 \%)$ developed BM at some point during their clinical course, and $32(14.7 \%)$ recurred in the brain as their first site of failure, and 15 (6.9\%) recurred in the brain as their exclusive site of failure. The 1-, 3-, and 5-year actuarial risk of developing BM were 9.2\%, $24.2 \%$, and $31.5 \%$, respectively. Our median time from surgery to onset of BM was 16 months (range, 2.5-68.5 months), longer than the reported 5.7-11.7 months [8-10,16,22,23]. In Stage IIIB NSCLC patients treated with PCI, lower BM and longer survival resulted from immediate concurrent chemoradiotherapy rather than induction chemotherapy-first regimens, which indicated the benefit of earlier PCI without delay because of induction protocols.[24] BM has a profound impact on morbidity and mortality.[9,11] Most patients who develop BM die of symptomatic intracranial tumor progression.[25,26] As extracranial control improves for LA-NSCLC, prophylaxis of BM becomes increasingly important.

Prior randomized [17-20] and nonrandomized [12,2731] trials evaluating PCI for NSCLC have consistently reported a significant decrease and/or delay in BM, but no benefit in OS. The latter has been attributed to poor locoregional and extracranial control and/or small study size. RTOG-0214 is the only randomized, controlled trial to investigate PCI in LA-NSCLC in the modern era of combined-modality therapy. In RTOG 0214, patients 
Table 2 Factors associated with the development of brain metastases

\begin{tabular}{|c|c|c|c|c|c|c|}
\hline \multirow[b]{3}{*}{ Factors } & \multicolumn{4}{|c|}{ Univariate analysis } & \multicolumn{2}{|c|}{ Multivariate analysis } \\
\hline & \multicolumn{3}{|c|}{ Incidence of BM (\%) } & \multirow[b]{2}{*}{$P$} & \multirow[b]{2}{*}{$P$} & \multirow[b]{2}{*}{ RR $(95 \% \mathrm{Cl})$} \\
\hline & $1-y r$ & $3-y r$ & $5-y r$ & & & \\
\hline \multicolumn{7}{|l|}{ Gender } \\
\hline Male & 7.6 & 20.5 & 26.9 & 0.012 & & \\
\hline Female & 13.3 & 33.4 & 43.0 & & & \\
\hline \multicolumn{7}{|l|}{ Age } \\
\hline$\leq 60 \mathrm{yrs}$ & 14.1 & 28.8 & 37.9 & 0.035 & & \\
\hline$>60$ yrs & 3.9 & 19.3 & 24.9 & & & \\
\hline \multicolumn{7}{|l|}{ Smoking History } \\
\hline Negative & 11.7 & 28.6 & 37.9 & 0.038 & & \\
\hline Positive & 7.2 & 21.0 & 26.8 & & & \\
\hline \multicolumn{7}{|l|}{ Histology } \\
\hline Non- squamous cell cancer & 12.0 & 34.6 & 44.3 & 0.000 & 0.001 & $4.13(1.86-9.19)$ \\
\hline Squamous cell cancer & 5.0 & 8.3 & 11.4 & & & \\
\hline \multicolumn{7}{|l|}{ Tumor stage } \\
\hline T1 & 5.9 & 20.1 & 36.1 & 0.596 & & \\
\hline $\mathrm{T} 2$ & 8.3 & 22.6 & 30.1 & & & \\
\hline T3 & 14.4 & 36.9 & 36.9 & & & \\
\hline \multicolumn{7}{|l|}{ Laterality } \\
\hline Left & 9.8 & 26.8 & 33.9 & 0.456 & & \\
\hline Right & 8.7 & 22.2 & 30.3 & & & \\
\hline \multicolumn{7}{|l|}{ Location } \\
\hline Upper/middle lobe & 7.8 & 22.3 & 31.7 & 0.798 & & \\
\hline Lower lobe & 11.5 & 27.2 & 31.6 & & & \\
\hline \multicolumn{7}{|l|}{ Histologic grade } \\
\hline Well/moderate & 8.8 & 21.7 & 31.1 & 0.601 & & \\
\hline Poor & 11.4 & 29.5 & 33.0 & & & \\
\hline \multicolumn{7}{|l|}{ Adjuvant chemotherapy } \\
\hline No & 11.0 & 21.2 & 24.7 & 0.511 & & \\
\hline Yes & 8.5 & 25.1 & 33.8 & & & \\
\hline \multicolumn{7}{|l|}{ Postoperative radiotherapy } \\
\hline No & 9.5 & 25.3 & 34.4 & 0.344 & & \\
\hline Yes & 8.7 & 23.0 & 29.0 & & & \\
\hline \multicolumn{7}{|l|}{ No. of metastatic lymphonodes } \\
\hline$\leq 5$ & 4.6 & 13.3 & 20.9 & 0.000 & & \\
\hline$>5$ & 14.5 & 38.6 & 46.3 & & & \\
\hline \multicolumn{7}{|l|}{ LNR } \\
\hline$\geq 30 \%$ & 15.3 & 39.2 & 46.4 & 0.000 & 0.000 & $3.33(1.79-6.18)$ \\
\hline$<30 \%$ & 2.9 & 10.3 & 18.4 & & & \\
\hline \multicolumn{7}{|c|}{ No. of metastatic mediastinal lymphonodes } \\
\hline$<3$ & 4.9 & 13.8 & 21.0 & 0.001 & & \\
\hline$\geq 3$ & 13.6 & 35.2 & 43.0 & & & \\
\hline
\end{tabular}

No. of metastatic mediastinal lymphonodes station 
Table 2 Factors associated with the development of brain metastases (Continued)

\begin{tabular}{lllll}
\hline 1 & 6.0 & 14.8 & 21.8 & 0.000 \\
$2-4$ & 15.1 & 42.7 & 51.6 & \\
Ratio of metastatic mediastinal lymphonodes station & & & & \\
$\leq 50 \%$ & 3.8 & 13.8 & 19.5 & 0.000 \\
$>50 \%$ & 15.0 & 35.8 & 44.9 & \\
\hline
\end{tabular}

$\mathrm{BM}$ indicates brain metastases; RR, relative risk; LNR, lymph node ratio.

with stage IIIA to IIIB NSCLC were eligible if they had stable disease or better after potentially curative therapy, defined as high-dose thoracic radiation therapy (RT; i.e., $>30$ Gy) or surgery.[20] The inclusion eligibility did not select the highest-risk population. Firstly, all kinds of NSCLC histology were included. Secondly, locoregional and extracranial distant relapse remains the major concern of the eligible stage IIIB and non-radically treated stage IIIA. Complete resection is a major curative therapy. Yet, only approximately $35 \%$ of all patients underwent surgery, and the proportion of complete resection was not provided. Besides, it is debatable to define RT $>30$ Gy as a potentially curative therapy. The risk of $\mathrm{BM}$ in the patient population of RTOG 0214 was not high enough to obtain a survival benefit from PCI. It is likely that locoregional and extracranial control was so poor that BM lacked the opportunity to manifest themselves. Future studies assessing PCI for NSCLC should be aimed at the highest-risk patients with satisfactory locoregional and extracranial control. Patients with stage

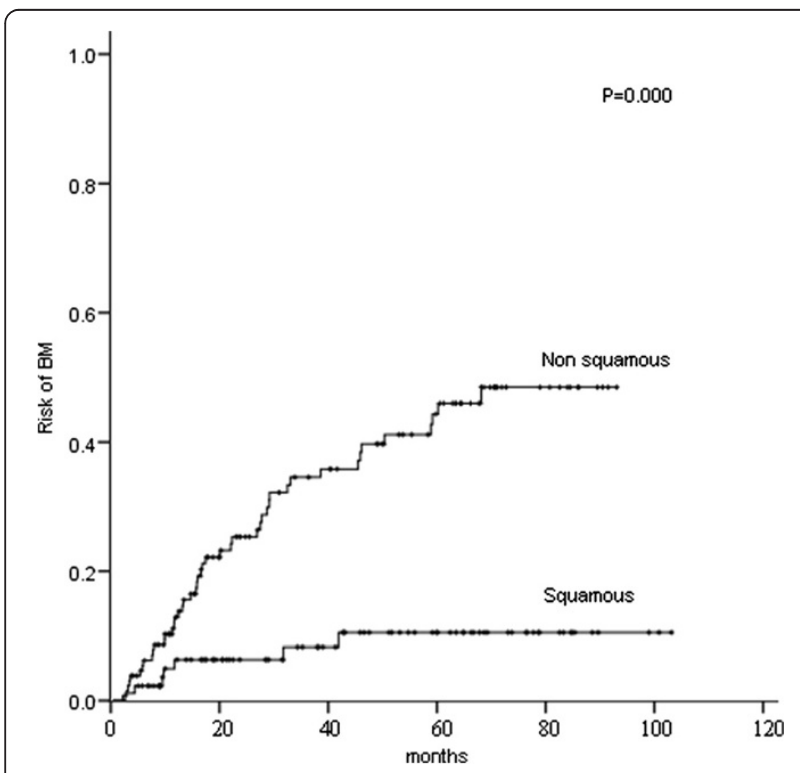

Figure 6 Comparison of the actuarial risk of developing brain metastases (BM) between squamous cell cancer and non squamous cell cancer.
IIIA (N2) made the radar. Moreover, radical resection is the most important curative treatment. In addition, primary surgery could provide accurate pathological stage. Hence, we targeted patients with completely resected PIIIA-N2 NSCLC.

Previous reports on risk factors of BM in NSCLC are inconsistent. The reported risk factors of BM in NSCLC include histology, [12,14-16,21,24] extent of disease,[10,13,22] adjuvant/neoadjuvant therapy, [12-15,22] younger age, $[8,10,23]$ incomplete resection,[13] and carcinoembryonic antigen serum level[32]. In our series, on multivariate analysis, non-squamous cell cancer histology and LNR $\geq 30 \%$ were associated with an increased risk of developing BM and $\mathrm{BM}$ as the first relapse. Non-squamous cell cancer as risk factor of $\mathrm{BM}$ and $\mathrm{BM}$ as the first relapse is consistent with many,[11,13-15,20,23,32-36] but not all,[7,8,10,12,19, 22,31,37-39] previous studies.

It is generally understood that patients with more severe nodal metastases, including stage, number, size, and region of metastatic lymph nodes, are at a higher risk for

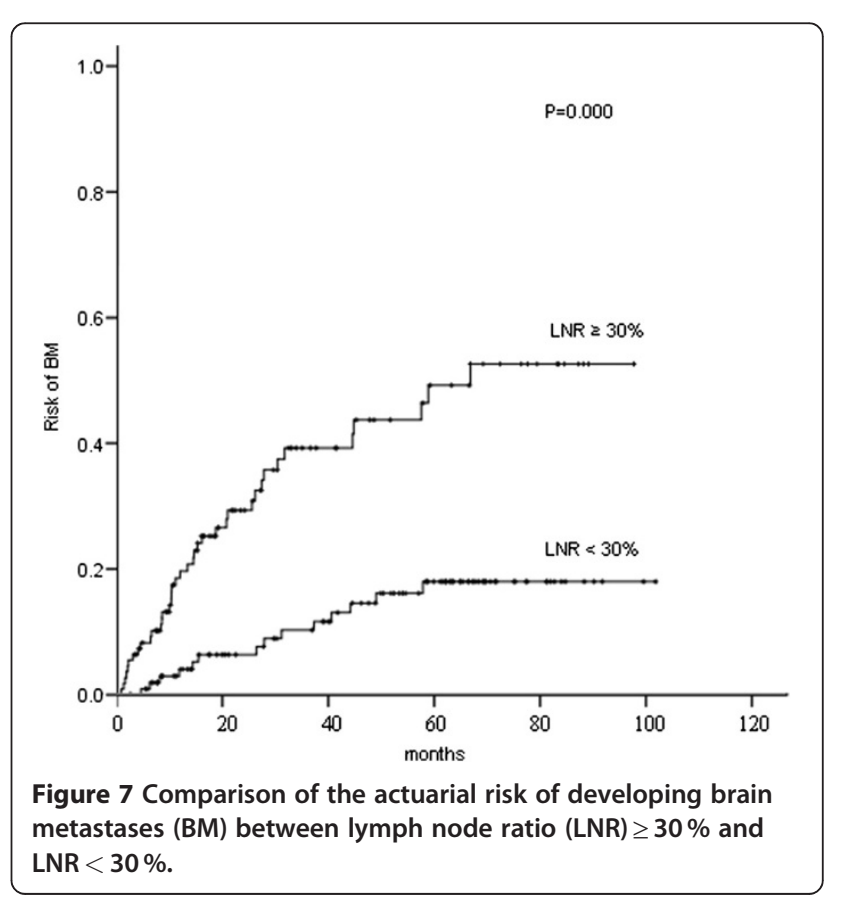




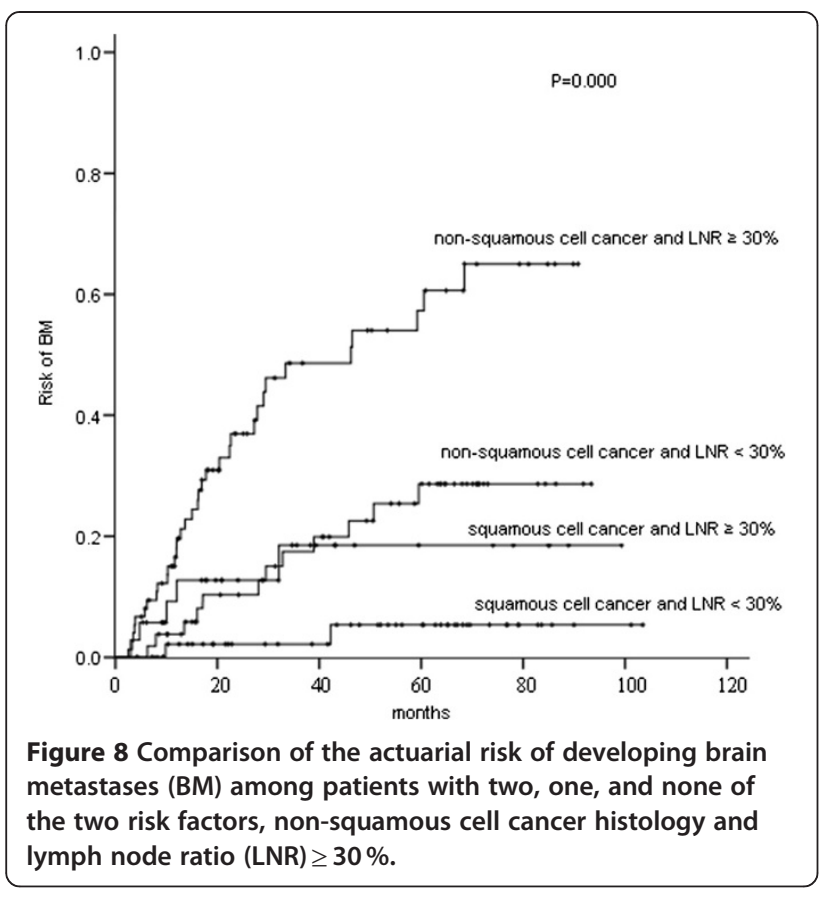

BM. Several studies reported increased BM risk correlated with increasing lymphonode stage.[1,23,30,34,35] Besides, Ceresoli et al. observed that clinical bulky $(\geq 2 \mathrm{~cm})$ mediastinal lymph nodes was of borderline significance in predicting an increased risk of BM in IIBIIIB NSCLC after multimodality treatment.[10] Wang et al. reported that a greater number of mediastinal lymph nodes and nodal regions with metastases predicted a higher risk of BM for stage III-N2 NSCLC.[13] Mamon et al. reported that the incidence of $\mathrm{BM}$ increased independently by the presence of residual nodal disease in 177 surgically treated IIIA (N2) NSCLC with/without neoadjuvant/adjuvant therapy.[11] In our study, on multivariate analysis, LNR $\geq 30 \%$ was associated with an increased risk of BM and BM as the first relapse. We are the first to introduce LNR into the assessment of risk of BM in NSCLC, and to find its predictive value. Recently, Matsuguma et al. reported that the LNR followed by the number of metastatic nodes may be more effective prognostic indicators than the current nodal classification based on the location of metastatic nodes, and should be considered in the future nodal classification of lung cancer.[40] Another very recent study using Surveillance, Epidemiology, and End Results (SEER) database confirmed that the LNR is an independent prognostic factor in patients with $\mathrm{N} 1$ NSCLC and suggested that LNR may be used to identify patients who are at greater risk of cancer recurrence.[41] We could not compare the predictive efficacy of LNR and the current nodal staging here, as our study focused on a homogenous population of completely resected
pIIIA-N2 NSCLC. Nonetheless, LNR might be a strong addition to the current nodal staging in predicting the risk of BM.

Tumor status is a major prognostic factor in NSCLC. Larger tumor size is associated with an increased risk of BM. [39] Bajard et al. demonstrated that in a cohort of 305 stage I-IIIB patients, T4 was related with a higher risk of BM, compared with T1-3.[34] However, many other investigators did not find that $\mathrm{T}$ status was significantly related with the risk of BM. $[10,12,14,15]$ We did not find such a relation, either. The studies that did not find the relation have a distinguishing characteristic in common: they almost exclusively included LA-NSCLC cases, which may explain the inconsistent results.

Multiple reports have demonstrated that systemic therapy increases the BM risk and prolongs OS. Cox et al.[15] and Wang et al.[13] indicated that adjuvant chemotherapy increases BM incidence in LA-NSCLC. In addition, several investigators $[9,12,14,22]$ found that an increased incidence of BM in patients treated with surgery is associated with neoadjuvant chemotherapy. Chemotherapy was not a statistically significant factor in our series. One of the reasons may be that the majority of our patients had undergone chemotherapy.

In our study, in patients with non-squamous cell cancer and LNR $\geq 30 \%(n=75)$, the 1-, 3-, and 5-year actuarial risk of developing BM was $18.1 \%, 48.6 \%$, and $57.3 \%$, respectively. Such a subset had sufficiently common BM rates to justify future trials on PCI. We are planning a randomized, controlled trial to investigate PCI in the highest-risk subset we identified. In that future study, we may consider including surgically staged IIIA (N2) non-squamous cell cancer with residual nodal involvement after neoadjuvant therapy based on the study by Mamon et al. [11].

Previous studies on risk factors of BM in NSCLC often include heterogeneous populations with respect to pre/postoperative stage and treatment, whereas we targeted a homogeneous population. In addition, compared with the previous studies, our data have more detailed information on the extent of nodal metastases and other clinical characteristics. Furthermore, to our knowledge, our report is the largest retrospective study focusing on risk factors of BM in completely resected pIIIA-N2 patients from a single institution, especially within a relatively recent and short time period (2003-2005). On the other hand, like all other retrospective analyses, our study has its limitations. The study may have selection bias and the results should be interpreted cautiously. Nevertheless, the high follow-up rate of 217 of 221 consecutively treated patients assures that the patients studied are highly representative of the patients with completely resected PIIIA-N2 NSCLC at our institution. Additionally, long follow-up and accurate pathological 
stage after primary surgery both could help draw a relatively convincing conclusion.

\section{Conclusions}

In NSCLC, patients with completely resected pIIIAN2 non-squamous cell cancer and LNR $\geq 30 \%$ are at the highest risk for $\mathrm{BM}$, and are most likely to benefit from PCI. Further trials on PCI should focus on highrisk subset.

\section{Competing interests}

The authors declare no competing interests.

\section{Authors' contributions}

XD drafted the manuscript. XD, HD, ZH, and $J$ participated in the coordination of the study, and helped to analyze the data. LW conceived of the study, participated in its design, and helped to analyze the data. All authors made substantial contributions to acquisition of data, and read and approved the final manuscript

An abstract about this work has been selected for Poster Viewing presentation during the 2011 ASTRO Annual Meeting.

\section{Author details}

${ }^{1}$ Department of Radiation Oncology, Cancer Hospital \& Institute, Chinese Academy of Medical Sciences and Peking Union Medical College, Pan jia yuan nan li 17\#, Chao yang District, Beijing 10021, China. ${ }^{2}$ Department of Thoracic Surgery, Cancer Hospital \& Institute, Chinese Academy of Medical Sciences and Peking Union Medical College, Beijing, China. ${ }^{3}$ Department of oncology, Provincial Hospital Affiliated to Shandong University, Jinan, China.

Received: 29 March 2012 Accepted: 14 July 2012

Published: 30 July 2012

\section{References}

1. Schouten LJ, Rutten J, Huveneers HAM, Twijnstra A: Incidence of brain metastases in a cohort of patients with carcinoma of the breast, colon, kidney, and lung and melanoma. Cancer 2002, 94:2698-2705.

2. Martini N, Bains MS, Burt ME, Zakowski MF, McCormack P, Rusch W, Ginsberg RJ: Incidence of local recurrence and second primary tumors in resected stage I lung cancer. J Thorac Cardiovasc Surg 1995, 109:120-129.

3. Newman SJ, Hansen HH: Frequency, diagnosis, and treatment of brain metastases in 247 consecutive patients with bronchogenic carcinoma. Cancer 1974, 33:492-496.

4. Sorensen JB, Hansen $H$, Hansen M, Dombernowsky P: Brain metastases in adenocarcinoma of the lung: frequency, risk groups, and prognosis. J Clin Oncol 1988, 6:1474-1480.

5. Komaki R, Scott CB, Sause WT, Johnson DH, Taylor SG: Induction cisplatin/ vinblastine and irradiation vs. irradiation in unresectable squamous cell lung cancer: failure patterns by cell type in RTOG 88-08/ECOG 4588. Int J Radiat Oncol Biol Phys 1997, 39:537-544.

6. Cox J, Yesner R: Adenocarcinoma of the lung: recent results from the Veterans Administration Lung Group. Am Rev Respir Dis 1979, 120:1025-1029.

7. Law A, Karp DD, Dipetrillo T, Daly BT: Emergence of increased cerebral metastasis after high-dose preoperative radiotherapy with chemotherapy in patients with locally advanced nonsmall cell lung carcinoma. Cancer 2001, 92:160-164.

8. Carolan H, Sun AY, Bezjak A, Yi QL, Payne D, Kane G, Waldron J, Leighl N, Feld R, Burkes R: Does the incidence and outcome of brain metastases in locally advanced non-small cell lung cancer justify prophylactic cranial irradiation or early detection? Lung Cancer 2005, 49:109-115.

9. Chen AM, Jahan TM, Jablons DM, Garcia J, Larson DA: Risk of cerebral metastases and neurological death after pathological complete response to neoadjuvant therapy for locally advanced nonsmall-cell lung cancer. Cancer 2007, 109:1668-1675.

10. Ceresoli GL, Reni M, Chiesa G, CARRETTA A, SCHIPANI S, PASSONI P, BOLOGNESI A, ZANNINI P, VILLA E: Brain metastases in locally advanced nonsmall cell lung carcinoma after multimodality treatment: risk factors analysis. Cancer 2003, 95:605-612.

11. Mamon HJ, Yeap BY, J nne PA, Reblando J, Shrager S, Jaklitsch MT, Mentzer S, Lukanich JM, Sugarbaker DJ, Baldini EH: High risk of brain metastases in surgically staged IIIA non-small-cell lung cancer patients treated with surgery, chemotherapy, and radiation. J Clin Oncol 2005, 23:1530-1537.

12. Stuschke M, Eberhardt W, P ttgen C, Stamatis G, Wilke H, St "-1ben G, St blen $F$, Wilhelm $H$, Menker $H$, Teschler $H$ : Prophylactic cranial irradiation in locally advanced non-small-cell lung cancer after multimodality treatment: Long-term follow-up and investigations of late neuropsychologic effects. J Clin Oncol 1999, 17:2700-2709.

13. Wang $S$, Ye X, Ou W, Lin Y, Zhang B, Yang H: Risk of cerebral metastases for postoperative locally advanced non-small-cell lung cancer. Lung Cancer 2009, 64:238-243.

14. Andre F, Grunenwald D, Pujol J, Girard P, Dujon A, Brouchet L, Brichon P, Westeel $V$, Le Chevalier T: Patterns of relapse of N2 nonsmall-cell lung carcinoma patients treated with preoperative chemotherapy. Cancer 2001, 91:2394-2400.

15. Cox JD, Scott CB, Byhardt RW, Emami B, Russell AH, Fu KK, Parliament MB, Komaki R, Gaspar LEW: Addition of chemotherapy to radiation therapy alters failure patterns by cell type within non-small cell carcinoma of lung: analysis of radiation therapy oncology group trials. Int J Radiat Oncol Biol Phys 1999, 43:505-509.

16. Komaki R, Scott CB, Byhardt R, Emami B, Asbell SO, Russell AH, Roach M, Parliament MB, Gaspar LE: Failure patterns by prognostic group determined by recursive partitioning analysis (RPA) of 1547 patients on four radiation therapy oncology group (RTOG) studies in inoperable nonsmall-cell lung cancer (NSCLC). Int J Radiat Oncol Biol Phys 1998, 42:263-267.

17. Cox JD, Stanley K, Petrovich Z, Paig C, Yesner R: Cranial irradiation in cancer of the lung of all cell types. JAMA 1981, 245:469-472.

18. Russell A, Pajak T, Selim H, Paradelo J, Murray K, Bansal P, Cooper J, Silverman S, Clement J: Prophylactic cranial irradiation for lung cancer patients at high risk for development of cerebral metastasis: results of a prospective randomized trial conducted by the Radiation Therapy Oncology Group. Int J Radiat Oncol Biol Phys 1991, 21:637-643.

19. Umsawasdi T, Valdivieso M, Chen TT, Barkley HT, Booser DJ, Chiuten DF, Dhingra HM, Murphy WK, Dixon CL, Farha P: Role of elective brain irradiation during combined chemoradiotherapy for limited disease nonsmall cell lung cancer. J Neurooncol 1984, 2:253-259.

20. Gore EM, Bae K, Wong SJ, Sun A, Bonner JA, Schild SE, Gaspar LE, Bogart JA, Werner-Wasik M, Choy H: Phase III comparison of prophylactic cranial irradiation versus observation in patients with locally advanced nonsmall-cell lung cancer: Primary analysis of Radiation Therapy Oncology Group Study RTOG 0214. J Clin Oncol 2011, 29:272-278.

21. Greene FL: AJCC cancer staging manual. New York: Springer; 2002.

22. Robnett TJ, Machtay M, Stevenson JP, Algazy KM, Hahn SM: Factors affecting the risk of brain metastases after definitive chemoradiation for locally advanced non-small-cell lung carcinoma. J Clin Oncol 2001, 19:1344-1349.

23. Gaspar LE, Chansky K, Albain KS, Vallieres E, Rusch V, Crowley JJ, Livingston $\mathrm{RB}$, Gandara DR: Time from treatment to subsequent diagnosis of brain metastases in stage III non-small-cell lung cancer: A retrospective review by the Southwest Oncology Group. J Clin Oncol 2005, 23:2955-2961.

24. Topkan E, Parlak C, Kotek A, Yuksel O, Cengiz M, Ozsahin M, Pehlivan B: Impact of Prophylactic Cranial Irradiation Timing on Brain Relapse Rates in Patients with Stage IIIB Non-small-cell Lung Carcinoma Treated with Two Different Chemoradiotherapy Regimens. Int J Radiat Oncol Biol Phys 2012, 83:1264-1271.

25. Borgelt B, Gelber R, Kramer S, Brady LW, Chang CH, Davis LW, Perez CA, Hendrickson FR: The palliation of brain metastases: final results of the first two studies by the Radiation Therapy Oncology Group. Int J Radiat Oncol Biol Phys 1980, 6:1-9.

26. Mandell L, Hilaris B, Sullivan M, Sundaresan N, Nori D, Kim JH, Martini N, Fuks $Z$ : The treatment of single brain metastasis from non-oat cell lung carcinoma: Surgery and radiation versus radiation therapy alone. Cancer 1986, 58:641-649.

27. Albain KS, Rusch VW, Crowley JJ, Rice TW, Turrisi AT, Weick JK, Lonchyna VA, Presant CA, McKenna RJ, Gandara DR: Concurrent cisplatin/etoposide plus chest radiotherapy followed by surgery for stages IIIA (N2) and IIIB non-small-cell lung cancer: mature results of 
Southwest Oncology Group phase II study 8805. J Clin Oncol 1995, 13:1880-1892.

28. Strauss GM, Herndon J, Sherman D, Mathisen D, Carey R, Choi N, Rege V, Modeas C, Green M: Neoadjuvant chemotherapy and radiotherapy followed by surgery in stage IIIA non-small-cell carcinoma of the lung: report of a Cancer and Leukemia Group B phase II study. J Clin Oncol 1992, 10:1237-1244.

29. Skarin A, Jochelson M, Sheldon T, Malcolm A, Oliynyk P, Overholt R, Hunt M, Frei E III: Neoadjuvant chemotherapy in marginally resectable stage III MO non-small cell lung cancer: Long-term follow-up in 41 patients. J Surg Oncol 1989, 40:266-274.

30. Jacobs RH, Awan A, Bitran JD, Hoffman PC, Little AG, Ferguson MK, Weichselbaum R, Golomb HM: Prophylactic cranial irradiation in adenocarcinoma of the lung a possible role. Cancer 1987, 59:2016-2019.

31. Pottgen C, Eberhardt W, Grannass A, Korfee S, St' ben G, Teschler H, Stamatis G, Wagner H, Passlick B, Petersen V: Prophylactic cranial irradiation in operable stage IIIA non-small-cell lung cancer treated with neoadjuvant chemoradiotherapy: Results from a German multicenter randomized trial. J Clin Oncol 2007, 25:4987-4992.

32. Arrieta O, Saavedra-Perez D, Kuri R, Aviles-Salas A, Martinez L, MendozaPosada D, Castillo P, Astorga A, Guzman E, De la Garza J: Brain metastasis development and poor survival associated with carcinoembryonic antigen(CEA) level in advanced non-small cell lung cancer: a prospective analysis. BMC cancer 2009, 9:119-127.

33. Perez CA, Pajak TF, Rubin P, Simpson JR, Mohiuddin M, Brady LW, Perez $\odot$ ITamayo R, Rotman M: Long-term observations of the patterns of failure in patients with unresectable non-oat cell carcinoma of the lung treated with definitive radiotherapy report by the radiation therapy oncology group. Cancer 1987, 59:1874-1881.

34. Bajard A, Westeel V, Dubiez A, Jacoulet P, Pernet D, Dalphin J, Depierre A: Multivariate analysis of factors predictive of brain metastases in localised non-small cell lung carcinoma. Lung Cancer 2004, 45:317-323.

35. Mujoomdar A, Austin JHM, Malhotra R, Powell CA, Pearson GDN, Shiau MC, Raftopoulos H: Clinical predictors of metastatic disease to the brain from non-small cell lung carcinoma: primary tumor size, cell type, and lymph node metastases. Radiology 2007, 242:882-888.

36. Figlin RA, PiAanta D: Intracranial recurrence of carcinoma after complete surgical resection of stage I, II and III non-small-cell lung cancer. N Engl J Med 1988, 318:1300-1305.

37. Keith B, Vincent M, Stitt L, Tomiak A, Malthaner R, Yu E, Truong P, Inculet R, Lefcoe M, Dar AR: Subsets more likely to benefit from surgery or prophylactic cranial irradiation after chemoradiation for localized nonsmall-cell lung cancer. Am J Clin Oncol 2002, 25:583-587.

38. Tang SGJ, Tseng CK, Tsay PK, Chen CH, Chang JWC, Pai PC, Hong JH: Predictors for patterns of brain relapse and overall survival in patients with non-small cell lung cancer. J Neurooncol 2005, 73:153-161.

39. Hubbs JL, Boyd JA, Hollis D, Chino JP, Saynak M, Kelsey CR: Factors associated with the development of brain metastases: analysis of 975 patients with early stage nonsmall cell lung cancer. Cancer 2010, 116:5038-5046.

40. Matsuguma H, Oki I, Nakahara R, Ohata N, Igarashi S, Mori K, Endo S, Yokol $K:$ Proposal of new nodal classifications for non-small-cell lung cancer based on the number and ratio of metastatic lymph nodes. Eur I Cardiothorac Surg 2011, 41:19-24.

41. Jonnalagadda S, Arcinega J, Smith C, Wisnivesky JP: Validation of the lymph node ratio as a prognostic factor in patients with $\mathrm{N} 1$ nonsmall cell lung cancer. Cancer 2011, 117:4724-4731.

\section{doi:10.1186/1748-717X-7-119}

Cite this article as: Ding et al.: Risk factors of brain metastases in completely resected pathological stage IIIA-N2 non-small cell lung cancer. Radiation Oncology 2012 7:119.

\section{Submit your next manuscript to BioMed Central and take full advantage of:}

- Convenient online submission

- Thorough peer review

- No space constraints or color figure charges

- Immediate publication on acceptance

- Inclusion in PubMed, CAS, Scopus and Google Scholar

- Research which is freely available for redistribution

Submit your manuscript at www.biomedcentral.com/submit
C Biomed Central 